\title{
A CONCEPTUAL MODEL FOR IMPROVED PROJECT SELECTION AND PRIORITISATION
}

\author{
P. J. Viljoen ${ }^{1}$ and H. Steyn \\ Department of Engineering and Technology Management \\ University of Pretoria, South Africa \\ herman.steyn@up.ac.za
}

\begin{abstract}
Project portfolio management processes are often designed and operated as a series of stages (or project phases) and gates. However, the flow of such a process is often slow, characterised by queues waiting for a gate decision and by repeated work from previous stages waiting for additional information or for re-processing. In this paper the authors propose a conceptual model that applies supply chain and constraint management principles to the project portfolio management process. An advantage of the proposed model is that it provides the ability to select and prioritise projects without undue changes to project schedules. This should result in faster flow through the system.
\end{abstract}

\section{OPSOMMING}

Prosesse om portefeuljes van projekte te bestuur word normaalweg ontwerp en bedryf as 'n reeks fases en hekke. Die vloei deur so 'n proses is dikwels stadig en word gekenmerk deur toue wat wag vir besluite by die hekke en ook deur herwerk van vorige fases wat wag vir verdere inligting of vir herprosessering. In hierdie artikel word ' $n$ konseptuele model voorgestel. Die model berus op die beginsels van voorsieningskettings sowel as van beperkingsbestuur, en bied die voordeel dat projekte geselekteer en geprioritiseer kan word sonder onnodige veranderinge aan projekskedules. Dit behoort te lei tot versnelde vloei deur die stelsel.

\footnotetext{
${ }^{1}$ This author was a staff member at the Department of Engineering and Technology Management at the University of Pretoria at the time of writing this paper.
} 


\section{INTRODUCTION}

Many project-based organisations manage a number of simultaneous projects that share resources from a limited pool. To manage such a situation, project portfolio management has recently received much attention. According to Cooper et al [1] this ensures that:

- the value of the portfolio is maximised - conducting the right projects,

- the portfolio is balanced - having the right mix of projects,

- the projects in the portfolio are aligned with strategy, and

- given the limited capacity available to work on projects, the correct number of projects is included in the portfolio.

Another recent development in the management of multiple projects is critical chain multi-project management (CCMPM) [2, 3, 4]. With this methodology many projects can be synchronised effectively around the schedule of one or a few key resources, producing a set of project schedules that are 'staggered' around the schedule of the key resource(s) - that is, project work is consciously delayed and released only according to the staggered project schedules. This technique is well described $[4,5]$.

The objective of this paper is to propose an enhancement to Cooper's model and to CCMPM through the placement and the management of buffers as an integral part of the pre-project process. This provides a mechanism to increase total system productivity.

For the proposed enhancement to be of value to practitioners, it needs to solve a fundamental problem inherent to existing models. The fundamental management problem is explained below.

\section{THE FUNDAMENTAL MANAGEMENT PROBLEM}

\section{Defining the fundamental management problem}

One of the problems that managers of portfolios of projects have to deal with when they use CCMPM to conduct their projects is the push-pull paradox, as described in Figure 1.

In Figure 1 the objective is indicated in block A. Two conflicting entities are indicated by blocks $\mathrm{D}$ and $\mathrm{D}$ '. Blocks $\mathrm{B}$ and $\mathrm{C}$ indicate two requirements for objective A. Entities D and D' are prerequisites for B and C respectively. The arrows between these blocks indicate causality - for example, "in order to have A we must have B", or "in order to have B we must have D". The callout boxes indicate assumptions relating to the causal relationships.

The objective of organisations that manage multiple projects concurrently is to continuously deliver as large a number of projects as possible in order to increase the value of the organisation. Value can be seen as the amount of money generated by the organisation over a given time (through sales) as well as return on the investment 
(ROI) required to generate such money. Money generated is equivalent to income generated through sales, or throughput as defined by Goldratt [6].

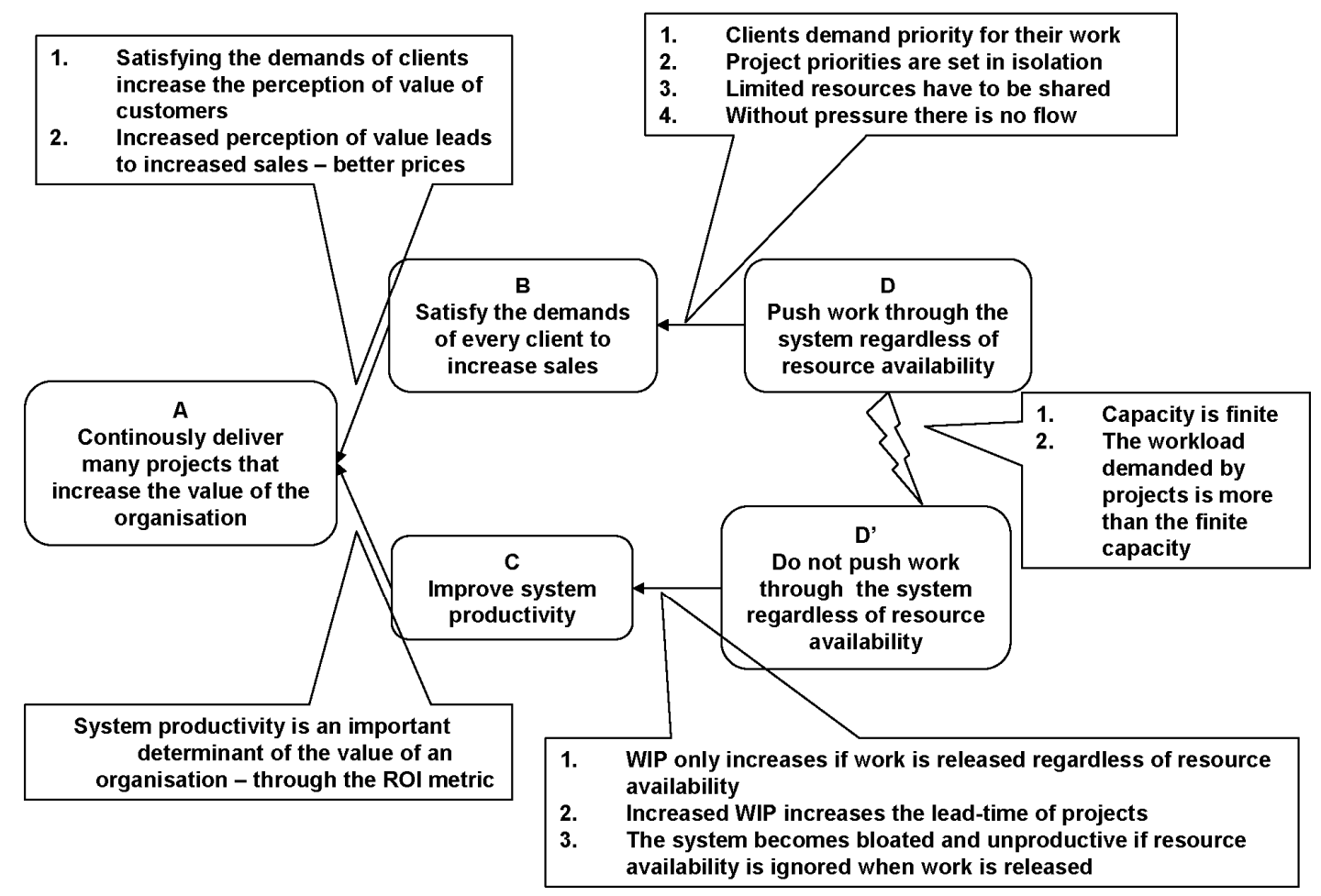

Figure 1: The management problem in project portfolios

To achieve this objective, two necessary conditions have to be satisfied:

- The demands of every client must be satisfied, because that increases their perception of value. It is assumed that an increased perception of value could lead to increased sales through better prices and more orders.

- $\quad$ System productivity must improve.

To satisfy the demands of every client, work is pushed through the system regardless of available resource capacity. This is because clients (and the project managers) demand that their work be given priority. Priorities are often set in isolation (not considering other projects) for the limited pool of shared resources.

To improve system productivity (the other necessary condition), work should not be pushed through the system regardless of resource availability. Here it is assumed that work-in-progress (WIP) increases if work is pushed into the system and that increased WIP slows down project delivery. It is further assumed that increased WIP bloats the system and causes it to become unproductive as inputs increase but outputs do not, as described by Wheelwright and Clark [13].

The paradox is clear - but it will only exist if available capacity is finite (resources are scarce) and when the workload demanded by the projects in the system exceeds the finite capacity. This is also illustrated by Sherwood [7] in a causal loop diagram. The organisation needs to push work into the system; but at the same time it must not 
push work through the system. This is the inherent dilemma of what is termed the push-pull paradox. When managers are confronted with this type of system paradox, and a solution seems to be unavailable ("it is the nature of the business"), one side of the paradox or conflict usually wins, implying that the other side loses. In reality, project work tends to be pushed through the system regardless of resource availability, because of a fear of losing business, the drive to maximise sales, high commissions paid to sales people or brokers, and the belief that "it can somehow be done”.

This problem demands considerable effort to solve, if it can be shown as being a fundamental or core problem. Should evidence exist that, due to this problem, a number of major negative effects exist in organisations, the problem could be viewed as fundamental and worth solving - in which case it would result in liberating the system of a number of major negative effects. Such support is provided in the next section.

\section{Support for the existence of a fundamental management problem}

Several authors $[8,9,10,11,12,13]$ highlight problems regarding the management of multiple projects. They typically highlight the issues of resource allocation, conflicting interests, and competition for limited resources among project managers. In a study of two cases that involved 30 and 60 simultaneous projects respectively, Engwall and Jerbrant [14] identified the following operational problems (or negative effects) in multi-project environments:

1. The senior managers responsible for portfolio management ("portfolio management level”) were overloaded with problems.

2. Portfolio management did priority setting and resource re-allocation on a daily basis (“...the primary every-day portfolio management issue was priority setting and resource re-allocation”).

3. "There was continuous ongoing negotiations concerning access to available resources and the allocation of certain individuals to specific projects."

4. "Management... was primarily engaged in short term problem solving."

5. Priorities of projects change often ("unclear project priorities" and "...issues concerning prioritization of projects and the distribution [of] personnel from lowprioritized, or smoothly going, projects to high-priority projects or projects in crises”, and “... nobody knew how to prioritize between them”).

6. One project had negative effects on other projects - such as delays and missed deadlines (“...project portfolios were characterised by extensive project interdependencies", "When one project had problems, other projects were affected directly...”, and "delays and disturbances within one project often had negative effects on several other projects as well”).

7. There was intense competition between projects and project managers who kept resources working on their projects (unnecessarily) in order not to lose them (“... from a project manager's point of view, acquired resources should be protected from other projects as long as possible, for instance by keeping them occupied, busy, and unavailable”). 
Figures 2 and 2a provide the logic that links the proposed problem to these negative effects. The diagram is read from the bottom to the top. The arrows are read as stating "if (activity at arrow tail) and (activity at arrow tail) then (activity at arrow head)". An ellipse around arrows indicates that the causes are sufficient to result in the effect indicated at the arrow heads.

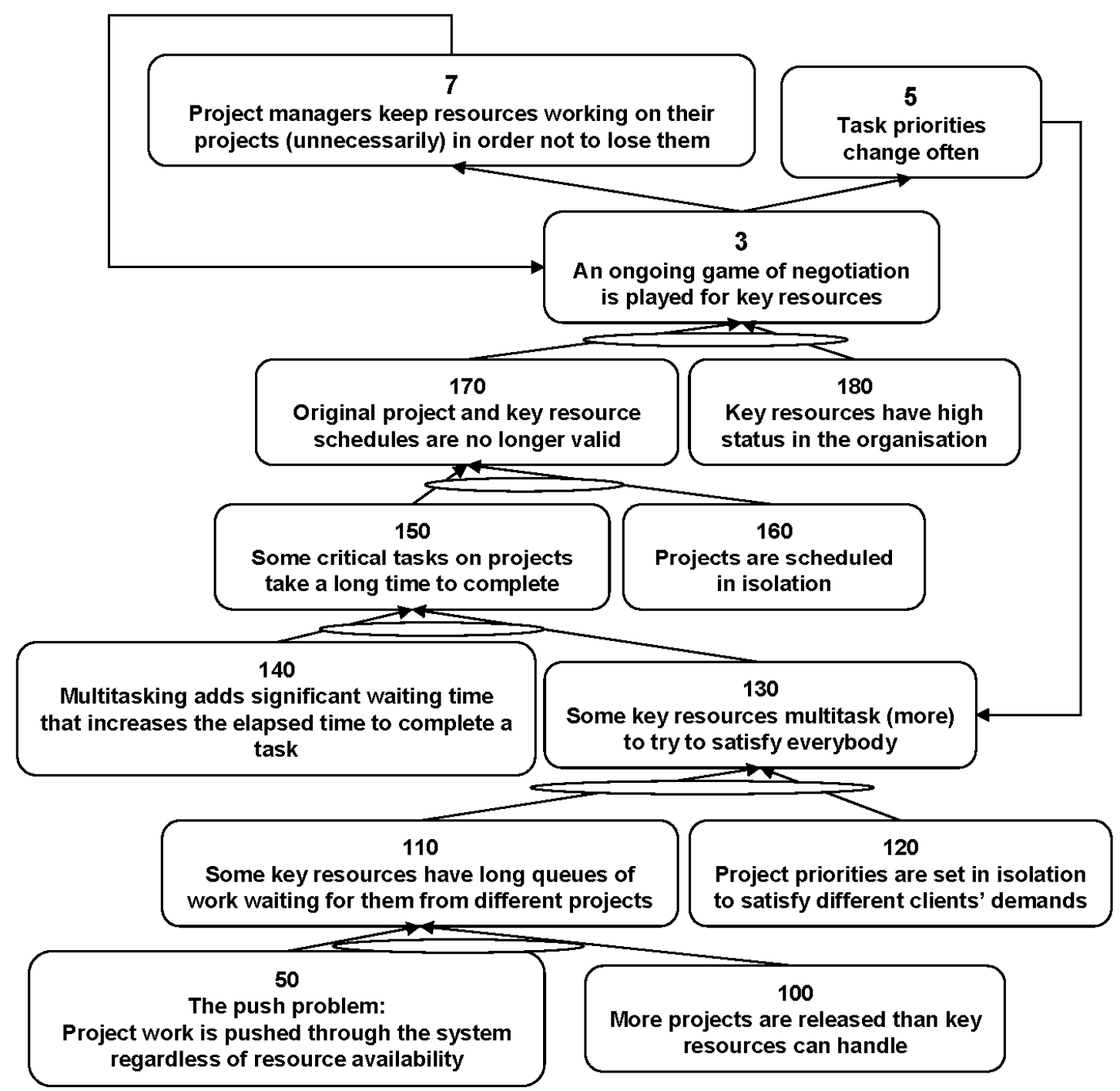

Figure 2: The logically derived effects of the fundamental problem

This logic validates the proposition that the management problem is fundamental to multi-project environments. The following description explains the logic (entities with single-digit numbers correspond to the negative effects identified by Engwall and Jerbrant [14]).

If project work is pushed through the system regardless of resource availability (the push-pull paradox) (50) and more projects are released than the capacity of key resources (100), then some key resources have long queues of work from different projects waiting for them (110). The work in these queues is prioritised based on project priorities that are set in isolation to satisfy the demands of different clients 
(120). The result is that certain key resources multitask (jump between tasks) to try to satisfy everybody (130). Multitasking adds significant waiting time that increases the elapsed time to complete a task (140). The effect is that some critical tasks on projects take a long time to complete (150). This causes original project and key resource schedules not to be valid any longer (170) since they were derived from project schedules that were done in isolation (160). Because key resources have a high status in the organisation (180), an ongoing game of negotiation is played as a result of the unreliable resource schedules (3). This causes task priorities to be changed often (5). It also often causes project managers to keep resources working on their projects (unnecessarily) in order not to lose them to other projects (7). The changed priorities cause more multitasking (130) and a negative spiral is established. If task priorities change (5) and project managers do not release resources from their projects when they are available (7), then one project has negative effects on other projects - such as delays (6). This problem is escalated to the portfolio managers who are responsible for delivery on many projects (200), causing them to do priority setting and resource re-allocation across projects on a daily basis (2). This again causes task priorities to change (5), which leads to more multitasking (130) and the negative spiral is reinforced. Senior management - responsible for portfolio management - is overloaded (1) and they are now primarily engaged in short term problem-solving (4). Their decisions regarding new opportunities on the early gates in the process are delayed and clouded by the short-term problems (220). The last effect follows logically, although it was not explicitly recognised by Engwall and Jerbrant [14].

This logic provides some evidence of the push-pull paradox being a fundamental one, and suggests that it is worthwhile to seek a solution. The four desired outcomes of project portfolio management as stated by Cooper [1] (maximum portfolio value, a balanced portfolio, strategy alignment, and the right number of projects) are in jeopardy if this problem cannot be resolved.

\section{EXISTING CONCEPTS AND MODELS}

\section{Flow systems}

Project portfolio management and multi-project management are in essence about managing a flow system. The desired outcome of a well-managed flow system is that a high quality product is delivered at the right time (when it is required by the customer) with a short lead-time. A flow system consists of interdependent parts (subsystems) and is subject to variability affecting each part [15]. Because different parts of the organisation are responsible for different subsystems, it often occurs that the subsystems are managed as if they were independent. The sales department, for example, is responsible for acquiring work (getting the job) while engineering departments are responsible for the quality of the product (design and build, doing the job). Project management is responsible for the successful delivery on contracts (completing the job), and for managing the flow; but it often experiences great difficulties satisfying the requirements of contracts (as defined in isolation by a commercial department). Over and above this, each one of these subsystems has to deal with the variation relating to their own work. 


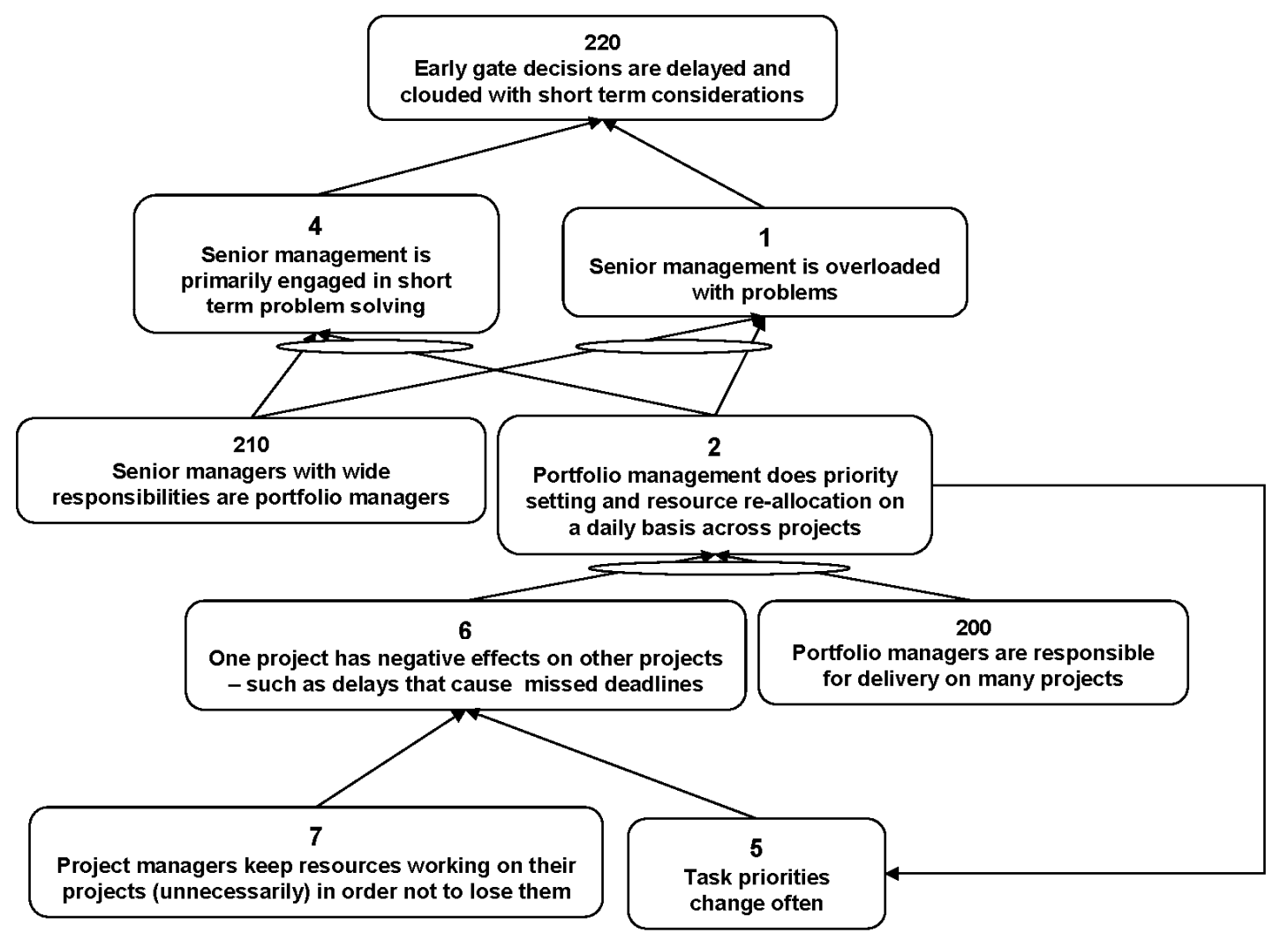

Figure 2a: The logically derived effects of the fundamental problem

A characteristic of any system that consists of dependent subsystems with variation within a subsystem is that variability accumulates, the further downstream one moves along the process [16]. The CCMPM methodology has been designed to manage such variability and dependency.

To develop the theoretical background for the proposed model, the analogy of a water reticulation system is used. An effective water reticulation system can be viewed as the perfect flow system or supply chain. While the efficiencies inherent in a water reticulation system are normally not present in typical portfolio management systems, this analogy provides an ideal to strive towards. The end user enjoys perfect service in the sense that quality water is available $100 \%$ of the time. The end user just needs to open the tap at any time, and water is supplied. This analogy serves to illuminate four principles which an effective flow system should reflect.

These are:

1. All parts of the system should be under some pressure. In water reticulation it is achieved through a system of pumps and reservoirs. The pipe to the tap is under pressure from a reservoir (buffer or inventory) at a higher elevation (or by a pressure vessel maintained at a certain pressure by a pump and pressure sensitive activation system). Water in the pipe to the reservoir is maintained at a certain pressure to enable instantaneous delivery as soon as water in the reservoir (buffer) drops to a certain level. 
2. Inventory should be kept as far upstream as possible for as long as possible. Most of the water is kept in the first storage facility, a dam or a lake. Here it remains until it is required to be released or pumped to that part of the reticulation system where water is needed - only when it is needed, not before.

3. Flow is as a result of some trigger (a pull signal) initiated at the end of the process. Somebody opens a tap somewhere, the water under pressure in the pipe flows out of the tap, causing the water level in the local reservoir high up in the building to drop, for example. This lowers the level (or reduces the pressure) in the reservoir and triggers a valve to open. Water flows from a supply pipe into the reservoir. The water flow reduces pressure in the pipe, causing the water level in the district reservoir to drop, and the trigger is propagated upstream to activate other parts of the system. This propagation only stops when the first storage facility is reached. In this analogy nature maintains the inventory in the most stream-up storage system (the dam or lake). Incidentally, the kanban pull system in JIT manufacturing also works on this principle [2].

4. The excess (protective) capacities of the upstream dependent subsystems and buffers should be sufficient to maintain the right pressure in the downstream pipes. Water will not flow when many taps are opened simultaneously, unless a certain amount of excess capacity is built into the whole system to accommodate this event, which can occur at any time (variability). The 'perfect' performance of the system (100\% availability all the time) can only be guaranteed if the required capacity of the subsystem furthest downstream (reticulation to end users) is used as the finite capacity (constraint) of the system that determines the capacities (including protective capacity) of all upstream subsystems.

The supply chains of perishable products are other examples of where these principles have been applied. The nature of the product (very short shelf life) forced the industry to adopt the principles.

The analogy described above provides the direction for a solution. The components of the solution are the following:

- the capacity constraint in the most downstream stage of the process,

- operates as a pull system;

- buffers (reservoirs) are appropriately placed to provide sufficient pressure and protection against variability, and

- protective capacity is in place at all processes upstream from the capacity constraint to ensure fast flow.

\section{Critical Chain Multi-Project Management (CCMPM)}

The CCMPM methodology employs time buffers in schedules to accommodate common cause variability within projects and between projects [17]. The effect that variability accumulates is thus neutralised where necessary. This implies that the work on each project is scheduled with aggressive duration estimates (a task has 
about a $50 \%$ chance of being completed within the estimated duration as well as about a $50 \%$ change of not being completed) and that a project is scheduled with protection against the cumulative effect of variability in the form of a project buffer (protection for tasks that are critical) and feeding buffers (protecting the critical tasks against delays of tasks that are not critical).

Where multiple projects are done with shared resources, a heavily loaded key resource (or a few key resources) is considered to be the constraint. Constraint resources are those resources of the organisation that embody its competitive advantage and whose productivity needs to be maximised to achieve maximum system productivity [16]. They are also referred to as drum resources.

Capacity buffers are included between the work on different projects for the capacity constraint resource(s) to protect one project against the variability of other projects. Projects are thus staggered on a time line, based on the aggressive estimates of workload on the constrained resource and capacity buffers.

\section{Cooper's stage-gate model}

The project flow process is often organised around stages (or project phases) and gates $[18,19]$. The analogy of a funnel is used: the mouth of the funnel represents the pre-project stages, while the neck of the funnel represents the projects being executed. While organisations should strive to have more projects in the early, exploratory stages, they should have fewer projects in the later project stages (the mouth of the funnel should be widened while the neck of the funnel should be narrowed) [20]. The reason for this is that selection criteria become more onerous and information becomes less uncertain at the later stages in the project lifecycle. Furthermore, the pressure on resources executing projects is reduced by the focus on selected, high-priority projects. To ensure that the rate of value delivery is maximised at the end of the funnel, and that reservoirs of work are available, a number of projects at different phases of their lifecycles should be worked on at any given point. A certain amount of pressure is therefore in place that is necessary to achieve flow in this pipeline. The question is how to maintain this pressure for the project pipeline.

\section{THE PROPOSED STAGE-GATE-BUFFER MODEL}

It can be assumed that work that needs to be done in any of the phases of the project lifecycle can be scheduled as a project or sub-project. For example, the feasibility stage of a project could be designed and scheduled as a sub-project; so could the conceptual and engineering design stages in a new product development process. With this assumption, the stage is now set to develop the conceptual stage-gatebuffer model for project portfolio management. Figure 3 depicts part of it: the details of the CCMPM system with a portfolio buffer supplying the pressure to a buffer for key resources - the work buffer. In the water reticulation analogy, the portfolio buffer is equivalent to the district reservoir. Without it, water would not be provided at the taps. 
Critical chain (CC) schedules for individual projects are used to determine workload for all resources. The workload on key resources (drum resources) is used to synchronise projects relative to one another, taking into account inter-project dependencies, project priorities, and capacity buffers. In this way work is effectively staggered for all project resources. Work in the buffer is scheduled, and is only released according to this schedule and the performance of key resources [17].

The flow in the system is controlled through downstream pull triggers. As a task is released from the work buffer to be executed (according to the multi-project schedule), a pull trigger is generated that releases a project or work from the upstream portfolio buffer. The project released from the work buffer is already planned and has passed through the final gate to ensure that it will deliver value. When the project passes the gate, it is included in the multi-project drum scheduling and becomes part of the work buffer. If a project does not pass the final gate (as a result, for example, of a cancelled order, changed needs, or technical obsolescence), a pull trigger is generated immediately to release the next project from the portfolio buffer, since no replenishment of the work buffer has occurred.

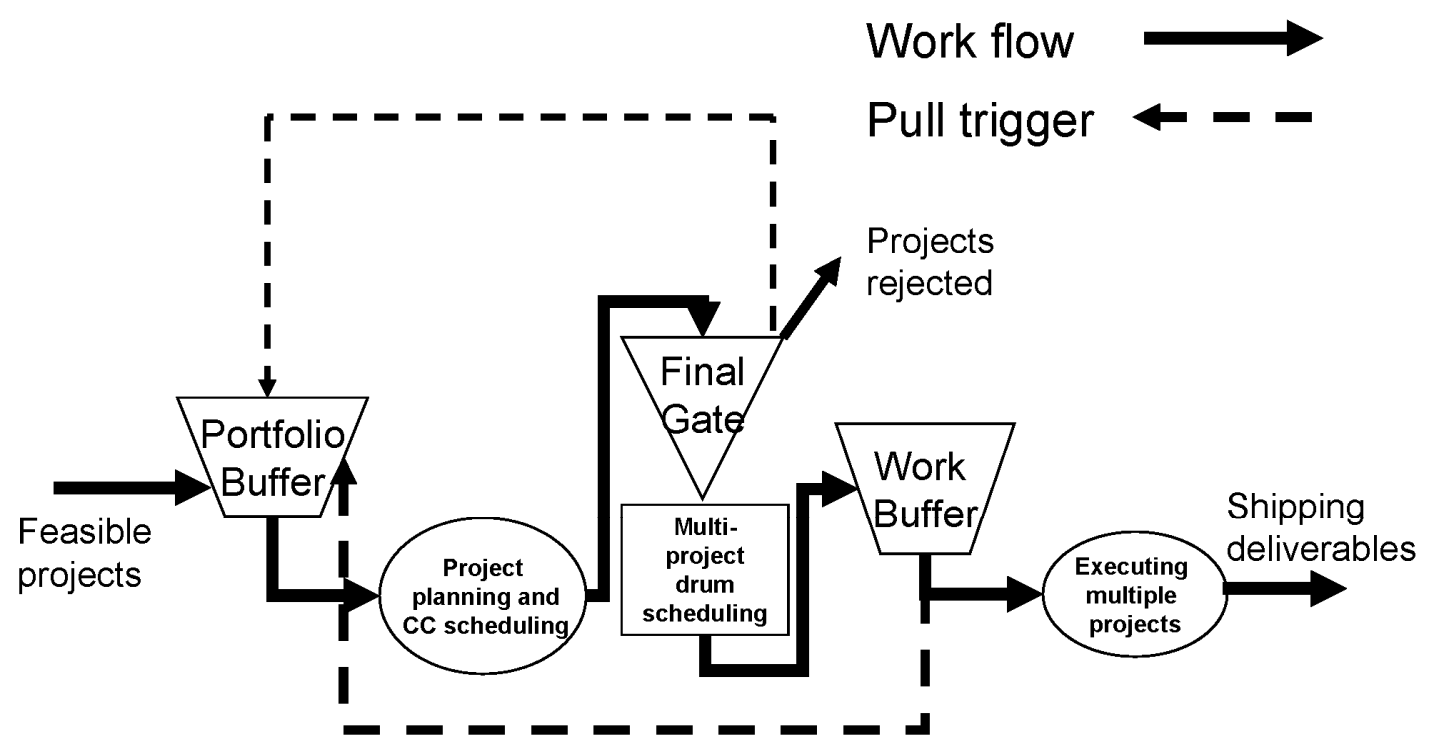

Figure 3: Critical chain multi-project scheduling

For a project to be released for project planning, a portfolio consisting of the right projects should be contained in the portfolio buffer. To be confident that the projects in the portfolio buffer are in fact the right projects, the buffer needs to be preceded by a gate where projects are selected and prioritised, i.e. the portfolio gate. The priorities will determine the sequence of release for project planning. The gate needs to be preceded by an exploration stage (feasibility, conceptual design, or other forms of exploration) that will provide the necessary information to make good decisions at the portfolio gate. The model is illustrated in Figure 4.

The following operating rules of the model need to be highlighted to explain the diagram: 
- Work, projects and proposals are pulled to the next stage by a trigger that is generated when work, a project, or a proposal is released from the downstream buffer.

- Any no-go decision (project rejected) at a gate provides a pull trigger.

- Work is not pushed to the next stage without a pull trigger.

- Gates are positioned before a buffer to ensure that what is contained in the buffer is a potentially valuable entity.

- Gates are operated (projects rejected or let through) as soon as the preceding stage of a project has been completed. Senior management act as gatekeepers. Good practice would be to schedule activities to accept or reject projects at the gate as part of the project plan. Any delays in making the go / no go decision would then reflect in the buffer status of the project and would be flagged for action.

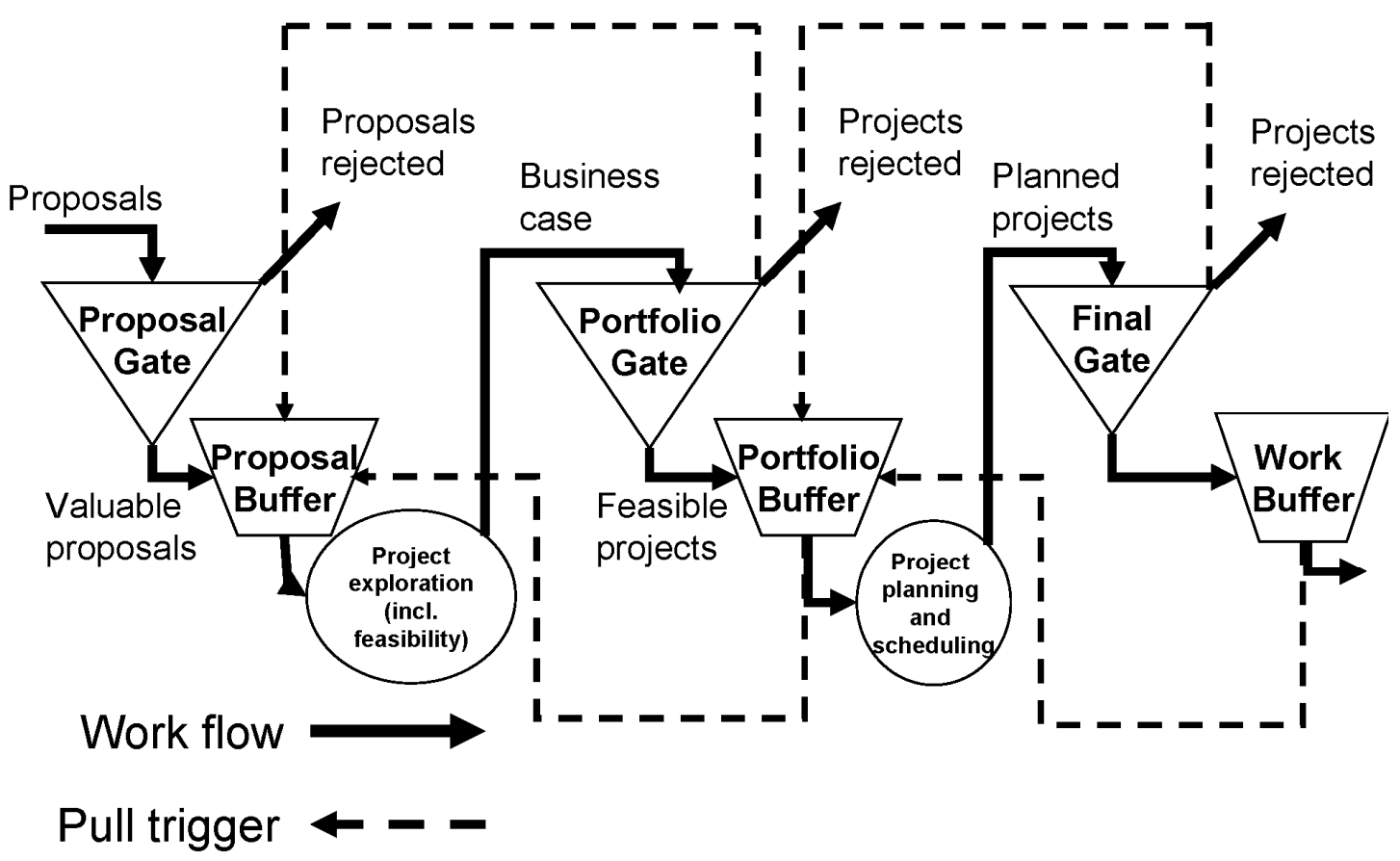

Figure 4: The proposed stage-gate-buffer model

Defining the details of each stage and gate is beyond the scope of this paper, as only a conceptual solution to the push-pull paradox is proposed.

However, two aspects of the model still have to be introduced to complete the concept - the sizing of the buffers, and the management of the flow through the buffers.

Buffer size is determined by the lead time between buffers. In a distribution system like water reticulation, the size of the reservoir or buffer is a function of the rate of release or consumption from the buffer and the time it takes to replenish the buffer. Another example: the size of the buffers that are needed at a distribution centre (DC) of fast-moving consumer goods would be equal to the rate of consumption of a 
product for all the retailers being served by the DC, within the time it takes to replenish the buffer from the manufacturer of the product. The time needed to replenish the buffer is a function of the frequency of order processing by the supplier, the frequency of transportation to the buffer, and the time to transport to the buffer. The size of any buffer is therefore determined by the downstream rate of use or consumption, and the upstream lead-time to replenish it.

In the context of the stage-gate-buffer model, it means that the buffer size of the work buffer is determined by the rate at which projects are delivered (derived from the drum - key resources - schedule), multiplied by the time it takes for a project to be designed and approved. These are stochastic variables that are subject to variation, and safety factors are needed to ensure that the buffer size is not too small, resulting in the buffer being depleted.

The size of the portfolio buffer is determined by the rate of release to the work buffer (again derived from the drum schedule) plus the rate at which projects are abandoned at the final gate (this should be relatively small, but cannot be ignored - it is likely that projects will be abandoned even at this late stage), multiplied by the time it takes to do the exploration and approval at the portfolio gate. The proposal buffer is sized in a similar way. The buffer size is expressed as a monetary unit if the throughput per project (as defined by Goldratt [6]) is known for all projects. If this is not known, the buffers are expressed as time buffers - i.e. the lead time from one buffer to the next. The discussion below of buffer management assumes that the size of buffers is expressed as value or throughput.

The second aspect that needs to be discussed is management of the flow through the system by monitoring buffer status. Buffer status indicates the health of the system, and is the input for controlling the system [6]. Buffer status fluctuates over time as consumption rates and replenishment rates vary. The effect is that, when a snapshot is taken of buffer status or content (project work or proposals in the buffer) at a point in time, some of that which might be expected to be there will not have arrived, and other content will be in the buffer, even though it was only expected later. To monitor the status of a buffer, the buffer (appropriately sized) is divided into three zones of equal size, labelled red, yellow, and green. Green indicates that there is sufficient work in the buffer to ensure availability; yellow indicates a possible imminent problem; while the red zone of a buffer indicates that management should take expediting decisions to ensure that the next process step is not be starved for lack of work (that is, they should expedite flow). If what was expected to be present in the yellow zone of the work buffer is not yet present, then expediting actions are planned but not yet taken. If what was expected to be present in the green zone of the buffer is not yet there, then no action is taken: the system is under control, and it is to be expected that, because of variation in the process, some work is delayed to some extent. In summary, if the value of work on hand for the next process step is less than one third of the buffer size, then the buffer status is red, and expediting actions need to be taken immediately. If the value of the work on hand for the next process step is more than two-thirds of the buffer size, then the buffer status is green - and it also suggests that the buffer may be too large. 
The stage-gate-buffer model can now be summarised as follows:

- The work rate of capacity constraint resources is defined as representative of system productivity.

- Projects are designed for all stages and scheduled with critical chain multiproject scheduling according to the work rate of the key resources, using duration estimates.

- A number of buffers are introduced before the respective stages of a stage-gate process.

- A work buffer ensures that key resources are most productively busy with the correct work.

- An upstream portfolio buffer maintains the work buffer.

- An upstream proposal buffer maintains the portfolio buffer.

- Work, projects, or proposals are released from a buffer only when a pull trigger is received from the downstream buffer, or when a pull trigger is received from the rejection of a project at a downstream gate.

- Buffers are appropriately sized.

- The system is controlled by monitoring the status of buffers - that is, buffer management.

This concludes the discussion of the conceptual solution to the push-pull paradox. What remains to be done is to provide support for the proposed solution, and to indicate research that might provide further validation and enhancements to the model.

\section{Support for the stage-gate-buffer model}

The model would be validated (to some extent) if it could be shown through logical reasoning that it solves the push-pull paradox, and that it eliminates the negative effects of the paradox, replacing them with positive effects. According to Theory of Constraints thinking processes, this implies that the push / don't push paradox has to be resolved [5], and that certain desired effects need to be caused by the model [21].

The paradox would be resolved if the proposed model invalidated one or more of the assumptions supporting it, as indicated in Figure 1. In this case, two assumptions are invalidated:

- The assumption that "the workload allocated to resources would be more than the finite capacity available" is invalidated. With the stage-gate-buffer model, the workload allocated to resources would be equal to the finite capacity of the most heavily-loaded resources.

- The assumption that project priorities are set in isolation is invalidated. At the portfolio gate, all projects are selected and prioritised, taking into account what is already in the portfolio buffer and in the work buffer. Projects are scheduled according to the load of the most heavily-loaded resources.

Both the necessary conditions - to satisfy the demand of clients, and to have a productive system - are satisfied, since work is pulled through the system from buffers that maintain work availability according to the work schedule of the most 
heavily-loaded resources - that is, at the fastest possible rate. The buffers also protect the system against variability. Multitasking of the key resources is reduced to a minimum, and project lead times are significantly shorter as a result. Project priorities are set and adjusted in the buffers before work is released, resulting in very few changes when work is carried out. As a result, project schedules (and therefore resource schedules) remain more valid within the leeway that is provided by feeding buffers, project buffers, and capacity buffers (which form an integral part of critical chain scheduling for single projects and for multiple projects). Undue changes in project schedules are thus eliminated. This protection of project schedules improves the ability to achieve promised due dates.

The virtual elimination of multi-tasking changes the causalities defined in Figure 2, and leads to the following new reality of desired effects (the opposites of the negative effects previously listed by Engwall and Jerbrant [14]):

1. Senior management, who are responsible for portfolio management, are not overloaded. Their involvement in the process is staggered, and involvement is only required when buffers are flagging "red" status.

2. The process of portfolio management sets priorities with clear information at the portfolio gate and portfolio buffer. Resource scheduling (allocation) is done as part of project and multi-project scheduling.

3. Negotiation for key resources is done as part of multi-project scheduling. Their schedules are the central point of control for the system as a whole, and are visible to everybody.

4. Management is primarily engaged in medium-term project selection and prioritising, while having to deal with short-term problems only in exceptional cases as signalled by buffer status. They are freer to devise strategies for which proposals are developed.

5. Priorities seldom change.

6. The interdependencies between projects are defined and taken into account with multi-project scheduling. If one project has to be delayed according to the finite capacity and protection required, this is communicated and negotiated with the client before the project is executed.

7. Project managers do not have to keep resources working on their projects in order not to lose them. Their projects are scheduled with the other projects in a way that maximises the productivity of key resources. Projects are continuously monitored to determine project buffer status. Based on the latest information, future work is rescheduled within the leeway provided by the buffers.

The above arguments could be considered as providing some support for the model, which needs to be further validated and enhanced through empirical research.

\section{CONCLUSION AND PROPOSED FURTHER RESEARCH}

The authors believe that the principles of this model could be useful in accelerating the flow of projects that are executed concurrently, and that it would increase the number of projects that an organisation is able to execute concurrently. It allows projects to be selected and prioritised without undue changes to schedules. It should 
also be possible to incorporate the principles of this model to develop more effective integrated management systems.

Case studies of organisations managing portfolios of projects should be carried out to confirm the premises of the model.

\section{REFERENCES}

[1] Cooper, R.G., Edgett, S.J. and Kleinschmidt, E.J. 2001. Portfolio management. Fundamental to new product success. Working Paper no 12. Product Development Institute.

[2] Chase, R.B., Aquilano, N.J. and Jacobs, F.R. 2001. Operations management for competitive advantage. $9^{\text {th }}$ Edition. McGraw-Hill.

[3] Goldratt, E.M. 1997. Critical chain. Creda Press, Cape Town.

[4] Newbold, R.C. 1998, Project management in the fast lane. St Lucie Press, Boca Raton.

[5] Hutchin, T. 2001. Enterprise-focused management. Changing the face of project management. Thomas Telford Publishing, London.

[6] Goldratt, E.M. 1990. The haystack syndrome. North River Press, New York.

[7] Sherwood, D. 2002. Seeing the forest for the trees: A manager's guide to applying systems thinking. Nicholas Brealey Publishing, London.

[8] Elonen, S. and Artto, K.A. 2003. 'Problems in managing internal development projects in multi-project environments', International Journal of Project Management, 21, pp 395-402.

[9] De Maio, A., Verganti, R. and Corso, M.A. 1994. 'Multi-project management framework for product development', European Journal of Operational Research, 78 pp 178-91.

[10] Platje. A., Seidel, H. and Wadman, S. 1994. 'Project and portfolio planning cycle: Project based management for the multiproject challenge', International Journal of Project Management, 12(2) pp 100-6.

[11] Hendriks, M., Voeten, B. and Kroep, L. 1995. 'Human resource allocation and project portfolio planning in practice', International Journal of Project Management, 38(4) pp 432-6.

[12] Payne, J.H. 1995. 'Management of multiple simultaneous projects: A state of the art review', International Journal of Project Management, 13(3) pp 163-8.

[13] Wheelwright, S.C. and Clark, K.B. 1992. 'Creating project plans to focus product development', Harvard Business Review March-April, pp 70-82.

[14] Engwall, M. and Jerbrant, A. 2003. 'The resource allocation syndrome: The prime challenge of multi-project management?' International Journal of Project Management. 21 pp 403-9.

[15] Schragenheim, E. and Dettmer, H.W. 2001. Manufacturing at warp speed. St. Lucie Press, Boca Raton.

[16] Goldratt, E.M. 1984. The goal. Creda Press, Cape Town.

[17] Leach, L.P. 2000. Critical Chain Project Management. Artech House, Boston p. 183-197.

[18] Cooper, R.G. 1993. Winning at new products. Accelerating the process from idea to launch. $2^{\text {nd }}$ edition. Addison-Wesley Publishing Company, Reading, $\mathrm{p}$ 163. 
[19] Cooper, R.G. and Kleinschmidt, E.J. 1993. 'Stage-gate systems for new product success', Marketing Management, 12(4), pp 20-29.

[20] Wheelwright, S.C. and Clark, K.B. 1992. Revolutionizing product development. Quantum leaps in speed, efficiency and quality. Free Press, New York.

[21] Scheinkopf, L.J. 1999. Thinking for a change. Putting the TOC thinking processes to use. St. Lucie Press, Boca Raton. 